\title{
ELABORAÇÃO E RESOLUÇÃO DE QUESTÕES PELOS ESTUDANTES: UM ESTUDO DE CASO ACERCA DE ASPECTOS COGNITIVOS E METACOGNITIVOS
}

\section{STUDENTS FORMULATING AND SOLVING QUESTIONS: A CASE STUDY ABOUT COGNITIVE AND METACOGNITIVE ASPECTS}

\author{
Marta Maximo Pereira ${ }^{1,2}$, Viviane Abreu de Andrade ${ }^{1,3}$ \\ ${ }^{1}$ Centro Federal de Educação Tecnológica Celso Suckow da Fonseca (CEFET/RJ) - UnED Nova Iguaçu \\ ${ }^{2}$ Doutoranda em Ensino de Ciências (modalidade Física), Programa de Pós-Graduação Interunidades em \\ Ensino de Ciências da Universidade de São Paulo (USP), \\ martamaximo@yahoo.com \\ ${ }^{3}$ Doutoranda em Ensino em Biociências e Saúde, Instituto Oswaldo Cruz - Fiocruz/RJ, \\ kange@uol.com.br
}

\begin{abstract}
RESUMO
Muitas pesquisas enfatizam a importância da metacognição para a aprendizagem de ciências. Apresentamos neste trabalho a análise de uma proposta de atividade em que os alunos são levados a elaborar e resolver uma questão relativa a conteúdos de Física estudados no ano anterior e a refletir sobre suas aprendizagens. Tal atividade foi aplicada, durante as aulas de Física, em uma turma de $2^{\circ}$ ano do Ensino Médio de uma instituição federal de ensino. Realizamos um estudo de caso, com abordagem qualitativa, por intermédio dos registros fornecidos por uma aluna. Ela realizou a atividade de forma apropriada e valeu-se de conhecimentos científicos e metacognitivos. Tal fato sugere que a relação entre aquilo que o sujeito conhece e aquilo que ele sabe sobre o que conhece, ou seja, entre cognição e metacognição, permite que nos aproximemos do problema concreto que é saber o que e como as pessoas aprendem.
\end{abstract}

Palavras-chave: Cognição, metacognição, elaboração de questões, aprendizagem, Física.

\begin{abstract}
A lot of researches emphasize the importance of metacognition to learn science. The analysis of an activity in which students are required to formulate a question about Physics contents they studied one year ago, to solve it and to reflect about their learning is presented in this paper. Such activity was carried out in a group of students in the second year of a public High School in Brazil, during Physics classes. A case study considering one student was done with a qualitative approach. The student solved the activity in an appropriate way and used scientific and metacognitive knowledge. It suggests that the relationship between what the student knows and what s/he knows about what s/he knows, it means, between cognition and metacognition, permits us to approach to the concrete problem of knowing what and how people learn.
\end{abstract}

Key words: Cognition, metacognition, question formulation, learning, Physics. 
Ensino, Saúde e Ambiente - V 7 (1), Edição Especial, maio de 2014

\section{INTRODUÇÃO}

Muitas pesquisas enfatizam a importância da metacognição para a aprendizagem de ciências (SCHRAW, CRIPPEN e HARTLEY, 2006; ROSA e PINHO ALVES, 2012). Revisando a literatura sobre essa temática, Zohar e Barzilai (2013) apontaram que "o campo da metacognição na educação em ciências está em estado de crescimento e expansão e que a metacognição está cada vez mais integrada à pesquisa sobre os objetivos fundamentais da educação científica" (p. 121).

Para esses autores, o desenvolvimento da metacognição pode auxiliar o processo de ensino e aprendizagem. Essa ideia está baseada na crença de que, quando os estudantes pensam sobre o que sabem (ou não), sobre quais são suas dúvidas (ou potencialidades) ou sobre como eles devem estudar para atingir seus objetivos de aprendizagem, é mais fácil controlar e monitorar suas aprendizagens e desenvolver estratégias para aprender.

Alguns trabalhos apresentam propostas de atividades para o desenvolvimento da metacognição dos estudantes (BEETH, 1998; WHITE e FREDERIKSEN, 2000; KOCH, 2001; SANTOS, SOUSA e INFANTE-MALACHIAS, 2008; SOLIVERES et $a l, 2011)$. Em nossa própria investigação (MAXIMO-PEREIRA e ANDRADE, 2012), apontamos que a escrita de uma autoavaliação "pode atuar como uma estratégia tanto de monitoramento e autorregulação cognitivos, auxiliando a aprendizagem, como um instrumento de pesquisa sobre metacognição" (p. 663).

Ademais, entendemos que o professor consegue avaliar os alunos de forma mais ampla se conhece as percepções deles sobre os conhecimentos que consideram ter aprendido. Uma tarefa que emerge desse entendimento, portanto, é o desenvolvimento de atividades que permitam ao docente ter indícios não somente do que o aluno sabe, mas também de como ele se apropriou do conhecimento e de quais são suas impressões sobre o que o levou a aprender.

Apresentamos neste trabalho a análise de uma proposta de atividade avaliativa em que os alunos são levados a elaborar e resolver uma questão de Física e a refletir sobre suas aprendizagens e sobre a própria atividade que lhes é solicitada. Tal atividade foi denominada Elaboração e resolução reflexivas de questões pelos estudantes e é um dos instrumentos de coleta de registros de uma pesquisa de doutorado em andamento. Ela foi aplicada, durante as aulas de Física, em uma turma de 20 alunos de $2^{\circ}$ ano do Ensino Médio de uma instituição federal de ensino, no ano de 2013. 


\section{FUNDAMENTAÇÃO TEÓRICA}

\section{Elaboração de perguntas e aprendizagem de ciências}

Assim como as perguntas são fundamentais para o desenvolvimento científico, também o são para o desenvolvimento cognitivo dos indivíduos, na forma de problemas (VIGOTSKI, 2009), e, especificamente, no processo de ensino e aprendizagem de ciências (MÁRQUEZ e ROCA, 2006). Para essas últimas autoras, "não se pode pretender que os alunos se engajem na cultura científica sem que se ensine a eles como elaborar problemas, fazer perguntas e, sobretudo, distinguir quais são as interessantes" (MÁRQUEZ e ROCA, 2006, p. 62).

De acordo com Márquez e Roca (2006), três aspectos devem ser considerados para a elaboração de boas perguntas, quais sejam: a necessidade de um contexto; a necessidade de dar indícios da teoria, modelo ou conceito implicado; a necessidade de elaborar uma demanda clara. Assim, toda pergunta deve conter indicadores implícitos ou explícitos que definam um contexto, que pode ser histórico, cotidiano, fantástico, etc. É necessário também identificar o motivo e o interlocutor da pergunta.

No que diz respeito ao segundo aspecto considerado, quando se objetiva que os alunos utilizem e relacionem, em suas respostas, aquilo que foi trabalhado nas aulas, a pergunta deve explicitar os elementos teóricos de referência a serem utilizados pelos estudantes. Tal característica é importante porque frequentemente uma mesma pergunta permite diferentes tipos e níveis de resposta, dependendo dos conceitos ou da teoria considerados (MÁRQUEZ e ROCA, 2006).

Por fim, a pergunta deve ser coerente com o que se quer perguntar, ou seja, deve expressar se é solicitada ao aluno uma definição, uma descrição, uma explicação, uma argumentação em favor de algo, etc.

\section{Aprendizagem de ciências e metacognição}

Ao reconstruir internamente o conhecimento compartilhado socialmente, o sujeito imprime nele a sua marca, atribuindo-lhe um sentido próprio, carregado de suas impressões e vivências anteriores. A apropriação ${ }^{1}$ do conhecimento pode, assim, vir acompanhada das reflexões pessoais do sujeito sobre seus processos cognitivos.

De acordo com Flavell, Miller e Miller (1999), a metacognição é definida de

\footnotetext{
${ }^{1}$ Segundo Smolka (2000, p. 28): “O termo apropriação refere-se a modos de tornar próprio, de tornar seu, tornar adequado, pertinente aos valores e normas socialmente estabelecidos. (...) 'fazer e usar instrumentos' numa transformação recíproca de sujeitos e objetos, constituindo modos singulares de trabalhar/produzir".
} 


\section{Ensino, Saúde e Ambiente - V 7 (1), Edição Especial, maio de 2014}

forma ampla como sendo o conhecimento ou atividade cognitiva que toma como seu objeto a cognição ou que regula qualquer aspecto da iniciativa cognitiva. Para os mesmos autores, a metacognição se refere tanto ao conhecimento metacognitivo (ou metaconhecimento) como ao monitoramento e à autorregulação cognitivos. Neste trabalho, focamos nossa análise nos tipos de metaconhecimento.

O conhecimento metacognitivo se refere ao conhecimento dos próprios recursos cognitivos. Ele pode ser subdividido em três dimensões: conhecimento sobre pessoas, sobre tarefas e sobre estratégias.

O metaconhecimento sobre pessoas, de acordo com Figueira (2003, p. 3), refere-se ao "conhecimento ou crença que a pessoa tem de si enquanto ser cognitivo, em tarefas cognitivas diversas, sobre os fatores ou variáveis que atuam ou interagem e de que maneiras afetam os resultados dos procedimentos cognitivos". A dimensão das tarefas diz respeito ao conhecimento que o sujeito tem sobre a natureza, as exigências e os critérios da atividade que irá realizar. Já o conhecimento metacognitivo sobre estratégias se relaciona com o conhecimento sobre os meios mais prováveis para se alcançar os objetivos cognitivos (FLAVELL, MILLER e MILLER, 1999). Para os autores, o metaconhecimento caracteriza-se por combinações ou interações de duas ou três dessas dimensões.

\section{METODOLOGIA DA PESQUISA}

\section{Caracterização da atividade proposta}

A atividade Elaboração e resolução reflexivas de questões pelos estudantes consistiu em solicitar que os estudantes elaborassem, considerando os conhecimentos de que dispunham, uma questão de Física e propusessem a resolução da mesma. Eles deveriam também escrever por que ou o que os levou a elaborar tal questão, ou seja, uma justificativa para o fato de terem escolhido determinado assunto e elaborado a questão da forma como o fizeram.

A proposta foi aplicada em uma turma de 20 alunos de $4^{\circ}$ período do curso de Ensino Técnico em Química Integrado ao Ensino Médio de uma instituição federal de ensino do estado do Rio de Janeiro, durante as aulas da disciplina Física IV. Os estudantes realizaram a atividade em sala de aula, individualmente, sem consulta a nenhum tipo de material e sem recorrer à ajuda nem dos colegas nem do professor. Os alunos poderiam escolher qualquer assunto estudado por eles durante as aulas da disciplina Física II ( $2^{\circ}$ período, aproximadamente um ano antes da solicitação da 


\section{Ensino, Saúde e Ambiente - V 7 (1), Edição Especial, maio de 2014}

atividade). A questão formulada poderia ser teórica, com cálculos ou com ambas as partes; a resposta deveria ser discursiva e devidamente justificada (respostas de múltipla escolha não eram permitidas). Os alunos foram orientados a não elaborarem questões de resolução imediata nem com enunciados muito diretivos, pois eles não deveriam ter pressa para realizar a atividade, que durou cerca de 30 minutos.

A atividade proposta aos estudantes possui caráter metacognitivo, sobretudo nas etapas de elaboração da questão e de justificativa de sua elaboração, mas também importante aspecto cognitivo. Entendemos que ambos se relacionam nesse contexto.

A elaboração da questão demandava do sujeito a reflexão acerca do que ele concebia como sendo um assunto conhecido (ou não) para ele. $\mathrm{O}$ aluno tendia a explicitar aquilo que considerava saber, o que pode revelar conhecimento metacognitivo sobre pessoas. A forma de escrita do enunciado da questão se relacionava com o modo como o aluno pretendia utilizar seus conhecimentos naquela situação (se por intermédio de cálculos, texto escrito, esquemas, figuras, etc., ou combinações desses elementos ou de outros que considerasse relevantes). Assim, valendo-se do conhecimento metacognitivo sobre estratégias, o aluno podia indicar alguns dos meios mais prováveis para atingir seus objetivos cognitivos.

Ainda sobre a elaboração da questão, é importante ressaltar que temos consciência de que as perguntas formuladas pelos estudantes nesta atividade não tinham por objetivo a construção de um novo conhecimento, a qual é uma característica geral das questões colocadas em ambientes de ensino e aprendizagem de ciências (MÁRQUEZ e ROCA, 2006). No entanto, entendemos ser também importante a formulação, pelos estudantes, de situações que dêem sentido aos conhecimentos considerados como previamente aprendidos por eles. Ainda que possam se inspirar em questões vistas anteriormente ou em explicações e exemplos do professor (o que, aliás, é bastante provável e interessante que ocorra) é importante disponibilizar aos estudantes um espaço para que tenham a possibilidade de se apropriar do conhecimento científico, imprimindo-lhe sua marca pessoal.

A resolução da questão visava a levantar indícios sobre o nível de apropriação do tema abordado e se o conhecimento que o aluno tinha sobre o assunto era compatível com o conhecimento científico. Entendemos que a justificativa para a elaboração da questão tende a fornecer elementos sobre o processo de aprendizagem do aluno, podendo ser compreendida na relação entre os conhecimentos metacognitivos sobre pessoas e sobre estratégias, pois o estudante tem a oportunidade de explicitar os 


\section{Ensino, Saúde e Ambiente - V 7 (1), Edição Especial, maio de 2014}

caminhos mais prováveis de que obtenha êxito em sua aprendizagem de acordo com seus próprios critérios e interesses.

Ao associarmos a questão elaborada à sua resolução, temos um indício sobre a metacognição dos estudantes de forma geral e de seu conhecimento metacognitivo sobre tarefas, pois ao ser capaz de resolver de forma adequada a questão que propôs com os conhecimentos de que dispõe, o aluno sinaliza conhecer os critérios da atividade.

\section{Caracterização da pesquisa}

Para analisar o desenvolvimento da atividade, realizamos uma investigação de caráter qualitativo (MOREIRA e CALEFFE, 2006). Foi feito um estudo de caso com os registros fornecidos por uma das alunas da turma investigada, a Aluna 16. Possíveis incorreções em seu texto foram mantidas, a fim de dispormos do material originalmente fornecido por ela.

Analisamos dados relativos à questão elaborada, à resposta e à justificativa da aluna, buscando evidenciar de que modo a atividade possibilitou a explicitação de aspectos cognitivos e metacognitivos por parte dela. Foram feitas também algumas inferências sobre a aprendizagem da aluna ao longo do tempo, pois a atividade foi proposta um ano após os primeiros contatos da turma com os assuntos de Física que poderiam ser abordados nela.

\section{ANÁLISE DE DADOS}

A questão elaborada pela Aluna 16 foi a que se segue:

Questão: Após uma inspeção a construção de uma importante passarela em uma grande cidade foi determinado pela equipe de fiscais que a passarela deveria ser destruída e a obra reiniciada. Em nota ao jornal local, o chefe de fiscalização informou: "Foi necessário exigirmos tais esforços por parte da equipe de construção... Observamos que as medidas dos espaços da passarela não eram satisfatórios e a passarela ofereceria grandes riscos a população." Explique, levando em consideração os conceitos de calor e dilatação, o porque de ser tão importante os espaços na passarela e de que forma e o que aconteceria se a passarela fosse mantida da forma que estava.

A aluna iniciou o enunciado da questão elaborando uma situação concreta, do cotidiano (Após uma inspeção a construção de uma importante passarela em uma grande cidade foi determinado pela equipe de fiscais que a passarela deveria ser destruída e a obra reiniciada.) para introduzir aquilo sobre o que pretendia perguntar. Foram criados pela aluna um ambiente (uma grande cidade), um objeto (passarela), personagens (equipe de fiscais), fatos concretos (inspeção, construção de uma importante passarela) e possibilidades de acontecimentos futuros (a passarela deveria 


\section{Ensino, Saúde e Ambiente - V 7 (1), Edição Especial, maio de 2014}

ser destruída e a obra reiniciada.). Na sequência, a estudante justificou a situação de destruição e reconstrução da ponte por intermédio da fala de um dos fiscais da obra a um jornal local (Foi necessário exigirmos tais esforços por parte da equipe de construção... Observamos que as medidas dos espaços da passarela não eram satisfatórios e a passarela ofereceria grandes riscos a população.).

Por intermédio dos elementos até então analisados, podemos identificar que a Aluna 16 caracterizou, por intermédio de uma narrativa, o contexto de sua questão, sendo esse um dos aspectos das boas perguntas para Márquez e Roca (2006).

A aluna escreveu que, de acordo com o fiscal da obra, os espaços da passarela não eram satisfatórios e a passarela ofereceria grandes riscos a população. É interessante notar que essa fala introduziu o aspecto científico (a dilatação da ponte) de forma indireta, mas com um argumento de autoridade conferido ao chefe da fiscalização. A justificativa para a alteração da ponte surgiu por intermédio de um personagem que parece possuir conhecimentos que sustentem a sua afirmação ao jornal.

No entanto, tais conhecimentos não são explicitados, mas sim perguntados pela aluna a quem vai resolver o problema (Explique, levando em consideração os conceitos de calor e dilatação, o porque de ser tão importante os espaços na passarela e de que forma e o que aconteceria se a passarela fosse mantida da forma que estava.). Com a expressão levando em consideração os conceitos de calor e dilatação, a Aluna 16 solicitou uma explicação com base na Física para o fato de os pequenos espaços entre as partes da passarela oferecerem perigo a quem passava por ela. A estudante citou, pela primeira vez, de forma explícita, os conceitos de calor e dilatação ${ }^{2}$, mencionando-os como tais e especificando que ambos seriam necessários à explicação da importância dos espaços ao longo de uma passarela. Mais uma característica de boas perguntas (MÁRQUEZ e ROCA, 2006) pode ser observada: a aluna deu informações no enunciado da questão sobre os conceitos a serem considerados em sua resolução.

Quando a aluna solicitou que se explicasse o porque de ser tão importante os espaços na passarela, ela mencionou implicitamente o fenômeno da dilatação térmica e colocou a principal demanda da pergunta: a explicação do fenômeno ocorrido com a passarela. Com a indagação de que forma e o que aconteceria se a passarela fosse mantida da forma que estava, ela solicitou a realização de uma previsão sobre o que

\footnotetext{
${ }^{2}$ Entendemos que o fenômeno da dilatação térmica (variação das dimensões de um corpo ou substância devido à variação de temperatura), ao qual a aluna se refere, envolve os conceitos de temperatura $\mathrm{T}$ (e sua variação $\Delta T$ ), de volume $\mathrm{V}$ e sua variação $\Delta V$, identificada por ela como dilatação.
} 


\section{Ensino, Saúde e Ambiente - V 7 (1), Edição Especial, maio de 2014}

aconteceria com a passarela se ela não fosse alterada. Em ambos os casos, fica claro sobre o que a aluna quer indagar com sua questão, o que evidencia a terceira característica de boas perguntas para Márquez e Roca (2006).

Em síntese, a aluna criou uma situação particular, passível de existência em seu cotidiano, no mundo real, para que, de alguma forma, se pudesse atribuir sentido aos conceitos científicos de calor e dilatação, elencados por ela como necessários à resolução da questão. A escrita do texto apresenta poucas incorreções e a situação que a Aluna 16 desenvolveu é coerente, apresentando início, meio e fim interconectados. A questão foi elaborada de forma apropriada pela aluna.

No que diz respeito à resposta que a Aluna 16 elaborou, é esta que se segue:

Os ferros usados para construir a passarela são bons condutores de calor e sofrem dilatação em seu volume. Em um ambiente quente, os ferros se dilatam de forma específica, até um certo limite. Se os espaços na passarela não fossem grandes o suficiente, no verão, esses ferros dilatariam expandindo a ponte, e haveria atrito entre as extremidades dos espaços o que poderia causar rachaduras e até um desabamento.

A aluna iniciou sua resposta indicando características do material usado para a construção da ponte (Os ferros usados para construir a passarela são bons condutores de calor e sofrem dilatação em seu volume.). No dado Os ferros... são bons condutores de calor, a aluna mencionou o fenômeno da condução térmica e identificou que o ferro é um bom condutor térmico. Em Os ferros... sofrem dilatação em seu volume, a Aluna 16 citou o fenômeno da dilatação térmica. Ela associou a dilatação térmica à variação de temperatura por duas vezes em seu texto, quais sejam: Em um ambiente quente, os ferros se dilatam e no verão, esses ferros dilatariam expandindo a ponte. Nesse último dado, ela identificou a dilatação com o aumento de tamanho da passarela.

A Aluna 16 atendeu à solicitação que colocou no enunciado da questão que elaborou, pois introduziu uma previsão sobre o que aconteceria se a passarela fosse mantida sem alterações: se os espaços na passarela não fossem grandes o suficiente, no verão, esses ferros dilatariam expandindo a ponte, e haveria atrito entre as extremidades dos espaços o que poderia causar rachaduras e até um desabamento.

A aluna também mencionou que poderia haver rachaduras na ponte devido à força de atrito que existiria entre as extremidades das placas de ferro, quando colocadas em contato por conta da dilatação sem o espaçamento adequado entre elas. Ela recorreu a um conhecimento de Mecânica (força de atrito) para complementar a sua resposta.

Em síntese, a Aluna 16 respondeu à questão que elaborou de forma apropriada, 


\section{Ensino, Saúde e Ambiente - V 7 (1), Edição Especial, maio de 2014}

expressando a previsão que solicitou no enunciado da questão e utilizando de modo adequado e consciente o conhecimento científico para a resolução da situação cotidiana que elaborou. Ela relacionou adequadamente a condução e dilatação térmicas e fez uma menção interessante à força de atrito, estudada por ela em Mecânica, em momento anterior às aulas de Física II. As corretas associações que fez entre diferentes conceitos e partes da Física parecem evidenciar o interesse da Aluna 16 pela temática que abordou na questão e por resolvê-la da forma mais completa e ampla possível.

Como justificativa para a elaboração da questão, a Aluna 16 escreveu:

Eu escolhi esse tema pois foi o que eu mais tive facilidade de aprender e também porque eu pude observar esse espaço nas passarelas e associar com o que vi em sala de aula na época em que estudei o assunto.

A Aluna 16 justificou por que selecionou o tema que foi utilizado na questão. Escolheu-o porque foi aquele que mais teve facilidade para aprender, porque pôde observar o espaçamento existente entre as placas que constituem uma passarela e porque pôde associar tal observação com o que viu em sala de aula. No dado foi o que eu mais tive facilidade de aprender, a Aluna 16 expressou consciência sobre o que aprendeu (ela sabe o que sabe) e sobre a facilidade que teve para aprender. Tais fatos são exemplos de conhecimento metacognitivo sobre pessoas, pois a aluna se reconheceu como ser cognitivo, apontando uma facilidade que teve para aprender.

Considerando o dado pude observar esse espaço nas passarelas e associar com o que vi em sala de aula, a aluna nos deu uma pista sobre a que se deveu a facilidade para aprender que ela expressou: a associação com o cotidiano. Assim, ela parece reconhecer o que a influenciou a aprender e a ter facilidade com o tema, o que associamos ao conhecimento metacognitivo sobre estratégias (FIGUEIRA, 2003).

No dado ...pude ...associar com o que vi em sala de aula na época em que estudei o assunto, a aluna identificou que as associações que fez com o cotidiano ocorreram já na época em que o assunto foi estudado inicialmente, na disciplina Física II, ou seja, que tais relações não foram estabelecidas agora, por conta da demanda da atividade a ser realizada pela Aluna 16.

Em síntese, a justificativa da Aluna 16 é adequada e parece indicar, mesmo que indiretamente, que a aluna sabia que deveria elaborar a questão com base naquilo que considerava saber, pois isso facilitaria a realização da atividade proposta. Em outras palavras, a aluna escolheu, para elaborar e resolver a questão, aquilo que identificou como tendo aprendido mais facilmente, o que reflete seu conhecimento metacognitivo 


\section{Ensino, Saúde e Ambiente - V 7 (1), Edição Especial, maio de 2014}

sobre tarefas, pois conhecia o critério da atividade que deveria realizar (elaborar uma questão que fosse capaz de resolver).

\section{CONSIDERAÇÕES FINAIS}

Neste trabalho, apresentamos a atividade Elaboração e resolução reflexivas de questões pelos estudantes e analisamos como a produção de um dos sujeitos nessa atividade colaborou para a explicitação de elementos cognitivos e metacognitivos relativos à aprendizagem de Física.

A Aluna 16 conseguiu propor uma questão cientificamente adequada e que, em sua forma, apresentou os três aspectos considerados importantes para a elaboração de perguntas (MÁRQUEZ e ROCA, 2006), quais sejam: presença de contexto, dos conceitos implicados para a sua resolução e de demanda clara. Pensamos que essa forma de elaboração do enunciado pode indicar com que tipo de questão ela se sentia mais confortável para expressar o que considerava saber.

O modo como formulou a questão e a sua justificativa para tal elaboração revelaram que a aluna atribuiu sentido ao conhecimento científico quando o mesmo a auxiliou no entendimento de uma situação cotidiana, próxima de sua realidade. Fazemos essa inferência pelo contexto da questão escrita pela aluna e por sua justificativa para tal elaboração. Em outras palavras, a aluna acreditou que aprendeu porque fez associação entre o que foi abordado em sala de aula e seu cotidiano e elaborou uma situação, também cotidiana, para expressar aquilo que considerava ter aprendido.

A resposta da aluna foi adequada à questão feita, pois a estudante explicou o fenômeno ocorrido na passarela, utilizando os conceitos elencados na pergunta, e respondeu à previsão solicitada na questão. Assim, entendemos que a presença dos três elementos (citados anteriormente) na questão elaborada não só revelou a qualidade da pergunta feita, mas também auxiliou na elaboração da resposta.

Além disso, a resposta da aluna é também compatível com o conhecimento científico, o que revela, do ponto de vista cognitivo, certo nível de apropriação dos conhecimentos envolvidos na questão por parte da aluna.

Considerando-se o aspecto metacognitivo, a relação entre a questão elaborada e sua solução levou-nos à interpretação de que a aluna soube escolher uma temática conhecida para ela, pois tinha consciência do que sabia. Dito de outra maneira, a Aluna 16 mobilizou conhecimento metacognitivo sobre pessoas no contexto analisado.

Sobre o fato de a aluna ter elaborado uma situação cotidiana no enunciado da 


\section{Ensino, Saúde e Ambiente - V 7 (1), Edição Especial, maio de 2014}

questão que versava sobre um assunto que acreditava conhecer, interpretamos que duas estratégias foram utilizadas para a realização da tarefa solicitada: utilizar um assunto que a aluna considerava saber e elaborar uma situação que lhe desse sentido, de acordo com os critérios da própria aluna. Assim, entendemos que a aluna utilizou também conhecimento metacognitivo sobre tarefas e estratégias, pois essas últimas foram elaboradas por conta da demanda da atividade proposta. Tal fato está de acordo com a compreensão de Flavell, Miller e Miller (1999) de que o conhecimento metacognitivo caracteriza-se por combinações ou interações das dimensões do metaconhecimento.

Por tudo isso, entendemos que o relativo êxito da aluna na realização da atividade proposta neste trabalho indica que tal atividade tem o potencial de contribuir para os processos de ensino e aprendizagem de ciências, pois concordamos com Márquez e Roca (2006) quando afirmam que

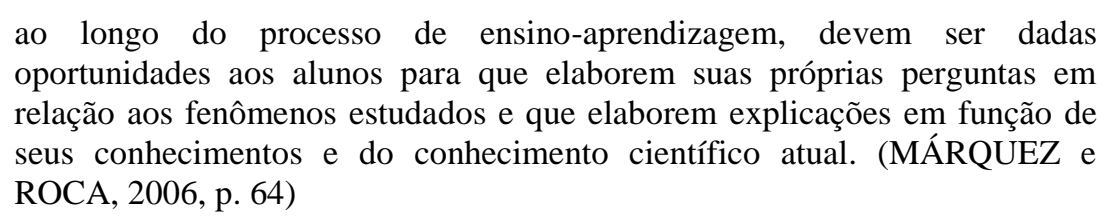

Ainda sobre as ideias dessas autoras sobre a formulação de perguntas na sala de aula de ciências, é interessante notar que esse trabalho considerava em sua análise as perguntas dos professores. Em nossa pesquisa, foi possível utilizar as características das boas perguntas, segundo Márquez e Roca (2006), para questões dos próprios estudantes, o que amplia a utilização desse trabalho na pesquisa em educação em ciências.

Sobre o desempenho da Aluna 16 na atividade proposta neste trabalho, entendemos que foram observados indícios de aprendizagem, pois a aluna retomou conhecimentos com os quais teve contato um ano antes da atividade realizada. Todavia, para entendermos por que a aluna elaborou a questão da forma que o fez, o que a levou a escolher a temática da questão e a acreditar que sabia aquele conhecimento, necessitaríamos de um estudo do processo ao longo do tempo, considerando como foram as interações da aluna com o professor, com os colegas e com o conhecimento científico na disciplina Física II.

Acreditamos que atividade Elaboração e resolução reflexivas de questões pelos estudantes pode contribuir para ampliar as formas de avaliação dos sujeitos implicados na educação científica e também como instrumento de pesquisa nesse campo, pois entendemos que a relação entre aquilo que o sujeito conhece e aquilo que 


\section{Ensino, Saúde e Ambiente - V 7 (1), Edição Especial, maio de 2014}

ele sabe sobre o que conhece, ou seja, entre cognição e metacognição, permite que nos aproximemos do problema concreto que é saber o que e como as pessoas aprendem.

\section{REFERÊNCIAS}

BEETH, M. E. Teaching for conceptual change: Using status as a metacognitive tool. Science Education. n. 82, p. 343-356, 1998.

FIGUEIRA, A. P. C. Metacognição e seus contornos. Revista Iberoamericana de Educación (Online), p. 1-20, 2003. Disponível em <http://www.rieoei.org/deloslectores/446Couceiro.pdf>. Acessado em maio de 2014.

FLAVELL, J. H.; MILLER, H. P.; MILLER, S. A. Desenvolvimento cognitivo. Porto Alegre: Artmed, Trad. Claudia Dornelles, 1999.

$\mathrm{KOCH}$, A. Training in metacognition and comprehension of physics texts. Science Education. n.85, p.758-768, 2001.

MÁRQUEZ, C.; ROCA, M. Plantear preguntas: un punto de partida para aprender ciencias. Revista Educación y Pedagogía. v. 18, n. 45, p. 61-71, 2006.

MAXIMO-PEREIRA, M.; ANDRADE, V. A. Autoavaliação como estratégia para o desenvolvimento da metacognição em aulas de ciências. Investigações em Ensino de Ciências, n.17, p. 663-674, 2012.

MOREIRA, H.; CALEFFE, L. G. Metodologia da pesquisa para o professor pesquisador. 2. ed. Rio de Janeiro: Lamparina, 2008. 245 p.

ROSA, C.W.; PINHO ALVES, J. Evocação espontânea do pensamento metacognitivo nas aulas de Física: estabelecendo comparações com as situações cotidianas. Investigações em Ensino de Ciências. v. 17, n. 1, p. 7-19, 2012.

SANTOS, D. B.; SOUSA, M.; INFANTE-MALACHIAS, M. E. Utilização do Modelo Didático Analógico em aulas de ciências: uma aproximação à prática docente. In: Anais do VIII Congresso Nacional de Educação da PUCPR - EDUCERE. Curitiba: PUCPR, 2008.

SCHRAW, G.; CRIPPEN, K. J.; HARTLEY, K. Promoting self-regulation in science education: Metacognition as part of a broader perspective on learning. Research in Science Education. n. 36, p. 111-139, 2006.

SMOLKA, A. L. B. O (im)próprio e o (im)pertinente na apropriação das práticas sociais. In: SMOLKA, A. L. B. Cadernos Cedes - Relações de ensino: análises na perspectiva histórico-cultural. n. 50, p. 26-40, 2000.

SOLIVERES, M. A.; GUIRADO, A. M.; BIZZIO, M. A.; MACÍAS, A. Intervenciones didácticas en clases de ciencias naturales mediante el uso de estrategias cognitivas y metacognitivas de lectura. Revista Electrónica de Enseñanza de las Ciencias. v. 10, n. 3, p. 420-437, 2011. 
VIGOTSKI, L.S. A construção do pensamento e da linguagem. 2. ed., São Paulo: WMF Martins Fontes, 2009.

WHITE, B.; FREDERIKSEN, J. Metacognitive facilitation: An approach to making scientific inquiry accessible to all. In J. Minstrell and E. van Zee (Eds.), Inquiring into Inquiry Learning and Teaching in Science. Washington, DC: American Association for the Advancement of Science, p. 331-370, 2000.

ZOHAR, A.; BARZILAI, S. A review of research on metacognition in science education: Current and future directions. Studies in Science Education.49(2), p. 121$169,2013$. 